\title{
Pseudo-backcrossing design for rapidly pyramiding multiple traits into a preferential rice variety
}

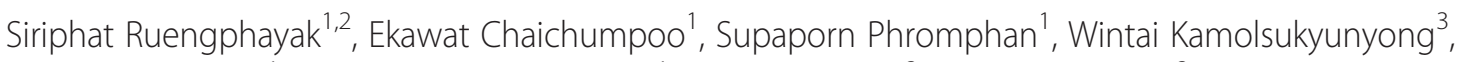
Wissarut Sukhaket ${ }^{1}$, Ekapol Phuvanartnarubal ${ }^{1}$, Siripar Korinsak ${ }^{3}$, Siriporn Korinsak ${ }^{3}$ and Apichart Vanavichit ${ }^{1,3,4^{*}}$

\begin{abstract}
Background: Pyramiding multiple genes into a desirable genetic background can take years to accomplish. In this paper, a pseudo-backcrossing scheme was designed to shorten the backcrossing cycle needed. PinK3, an aromatic and potentially high-yielding rice variety-although one that is intolerant to flash flooding (Sub) and susceptible to bacterial leaf blight (BB), leaf-neck blast (BL) and the brown planthopper (BPH)—was used as a genetic basis for significant improvements through gene pyramiding.

Results: Four resistance donors with five target genes (Sub1A-C, xa5, Xa21, TPS and SSIIa) and three QTLs (qBph3, qBL1 and qBL11) were backcrossed individually using markers into the pseudo-recurrent parent 'PinK3' via one cycle of backcrossing followed by two cycles of pseudo-backcrossing and three selfings with rigorous foreground marker-assisted selection. In total, 29 pseudo-backcross inbred lines (BILs) were developed. Genome composition was surveyed using 61 simple sequence repeats (SSRs), 35 of which were located on six carrier chromosomes, with the remainder located on six non-carrier chromosomes. The recurrent genome content (\%RGC) and donor genome content (\%DGC), which were based on the physical positions of $\mathrm{BC}_{1} \mathrm{~F}_{2}$, ranged from 69.99 to $88.98 \%$ and 11.02 to $30.01 \%$, respectively. For the pseudo- $\mathrm{BC}_{3} \mathrm{~F}_{3} \mathrm{BILS}$, the $\% \mathrm{RGC}$ and $\% \mathrm{DGC}$ ranged from 74.50 to $81.30 \%$ and 18.70 to $25.50 \%$, respectively. These results indicated that without direct background selection, no further increases in \%RGC were obtained during pseudo-backcrossing, whereas rigorous foreground marker-assisted selection tended to reduce linkage drag during pseudo-backcrossing. The evaluation of new traits in selected pseudo- $\mathrm{BC}_{3} \mathrm{~F}_{3} \mathrm{BILs}$ indicated significant improvements in resistance to $\mathrm{BB}, \mathrm{BL}, \mathrm{BPH}$ and Sub compared with PinK3, as well as significant improvements in grain yield (21-68\%) over the donors, although yield was 7-26\% lower than in 'PinK3'. All pyramided lines were aromatic and exhibited improved starch profiles, rendering them suitable for industrial food applications.
\end{abstract}

Conclusions: Results show that our new pyramiding platform, which is based on marker-assisted pseudo-backcrossing, can fix five target genes and three QTLs into a high-yielding pseudo-recurrent background within seven breeding cycles in four years. This multiple pseudo-backcrossing platform decreases the time required to generate new rice varieties exhibiting complex, durable resistance to biotic and abiotic stresses in backgrounds with desirable qualities.

Keywords: Gene pyramiding; Multiple backcrossing; Submergence tolerance; Bacterial leaf blight resistance; Blast resistance; Brown planthopper resistance; Linkage drag; Pseudo-backcrossing; Recurrent genome content; Donor genome content

\footnotetext{
* Correspondence: vanavichit@gmail.com

${ }^{1}$ Rice Science Center, Kasetsart University, Kamphaeng Saen, Nakhon Pathom

73140, Thailand

${ }^{3}$ Rice Gene Discovery, National Center for Genetic Engineering and

Biotechnology (BIOTEC) National Science and Technology Development

Agency (NSTDA), Kasetsart University, Kamphaengsaen, Nakhon Pathom

73140, Thailand

Full list of author information is available at the end of the article
}

\section{国

(c) 2015 Ruengphayak et al.; licensee Springer. This is an Open Access article distributed under the terms of the Creative Commons Attribution License (http://creativecommons.org/licenses/by/4.0), which permits unrestricted use, distribution, and reproduction in any medium, provided the original work is properly credited. 


\section{Background}

Rice (Oryza sativa L.) is an important staple food crop and a major part of the diet of more than half of the world's population. Approximately $90 \%$ of rice is grown in Asia. Worldwide, approximately 79 million ha of irrigated lowland rice provides $75 \%$ of the world's rice production (Maclean et al. 2002; Bouman et al. 2007). Therefore, irrigated rice remains the most important production system for maintaining food security, particularly in Asian countries. Rice production in irrigated areas of Thailand has been frequently and strongly affected by abiotic stresses resulting from unfavorable climatic changes, such as flooding and drought, as well as by biotic stresses caused by bacterial leaf blight (BB), leaf/neck blast (BL) and brown planthopper (BPH). Therefore, new successful breeding lines must possess multiple types of resistance to both biotic and abiotic stresses, as well as demonstrating specific grain qualities and high yield.

Three popular breeding methods used for gene pyramiding are pedigree, backcrossing and recurrent selection. In cross-pollinating crops, gene pyramiding is accomplished through recurrent selection. Successful quantitative trait locus (QTL) introgression depends on the optimized expression of newly introgressed QTLs in the recipient genome background, with the aim of maximizing productivity. A general framework for addressing these considerations through the pyramiding of multiple QTLs into a single favorable genetic background has been proposed, although such techniques are time-consuming (Servin et al. 2004).

To pyramid several new QTLs, stepwise crossing schemes can be designed, although such schemes can require many generations of breeding. If the ultimate goal is to improve a specific desired variety, parallel backcrossing of single donors can most effectively be carried out using both foreground and background selection. Recently, successful gene/QTL pyramiding programs were reported in Thai Jasmine (Win et al. 2012; Luo and Yin, 2013), Basmati (Singh et al. 2012; Singh et al. 2013), Koshihikari (Ashikari and Matsuoka, 2006; Tomita, 2009), Zhenshan 97 (Wang et al. 2012) and 93-11 (Zong et al. 2012) rice varieties. However, when the target traits are quantitatively controlled, combining several QTLs can take years to accomplish. For multiple QTL pyramiding, three phases are necessary: the creation of near-isogenic lines (NILs), genotype assembly, and the extraction of pure lines. Specific backcrossed recombinant inbred lines (RILs) carrying four main-effect QTLs and four epistatic-effect QTLs were pyramided into the elite cultivar Zhenshan97 (Wang et al. 2012). To combine greater numbers of QTLs, marker-assisted phenotypic selection (MAS) has been developed, which is a novel approach for QTL pyramiding of up to 24. QTLs from a single crossing (Zong et al. 2012). QTL pyramiding via NILs was successfully used to improve disease and lodging resistance, as well as to increase the harvest index (Luo and Yin, 2013). However, all of these approaches require many years to complete.

To shorten the backcross breeding cycle, we propose a modified form of pseudo-backcrossing. The original design of pseudo-backcrossing originated from tree breeding methods, where $F_{1}$ plants resulting from a single cross are backcrossed to alternate recurrent parents to avoid inbreeding depression (Bouquet 1986). Pseudobackcrossing is commonly used in perennial plants, including grape (Molnár et al. 2007), eucalyptus (Kullan et al. 2012), poplar (Novaes et al. 2009) and oil palm (Montoya et al. 2014). For multiple gene/QTL pyramiding, several donors are used to create newly improved genotypes; however, the need to maintain the preferred genetic background is equally important. Therefore, the introduction of pseudo-backcrossing could benefit multiplex gene pyramiding.

Most rice varieties are not tolerant to flash flooding. Submergence tolerance is determined by the major Sub1QTL on chromosome 9 with relatively high heritability. The new Thai jasmine rice variety 'Khao Dawk Mali 105 (KDML105)' was developed for submergence (Sub) tolerance using marker-assisted backcross breeding $(\mathrm{MAB})$ and has been released to farmers (Siangliw et al. 2003). Growing rice plants also suffer from epidemic diseases such as rice blast (BL) and bacterial leaf blight (BB). Rice BL, which is caused by the fungal pathogen Pyricularia oryzae (teleomorph: Magnaporthe oryzae), is a major rice disease in irrigated rice-growing areas worldwide (Ou 1985). QTLs for broad-spectrum resistance to rice $\mathrm{BL}$ have been reported on chromosomes 1 and 11 from JHN and on chromosomes 2 and 12 from IR64 (Sirithunya et al. 2002; Noenplab et al. 2006; Sreewongchai et al. 2010). Major effective QTLs for Thai blast isolates were located on chromosomes 1 and 11, which are flanked by RM212 and RM319 on qBL1 and by RM224-RM144 on qBL11 (Noenplab et al. 2006; Wongsaprom et al. 2010). The presence of qBL1 and qBL11 have strong effects on blast resistance in Thailand. BB, which is caused by the bacterium Xanthomonas oryzae pv oryzae can be effectively controlled using resistant varieties. Several resistance genes, including $X a 4, x a 5$ and Xa21, are effective sources of resistance for marker-assisted gene pyramiding in rice (Korinsak et al. 2009b; Suh et al. 2013).

Among insect rice pests, the brown planthopper $(\mathrm{BPH}$, Nilaparvata lugens $\mathrm{Sta}^{\circ} \mathrm{l}$ ), is considered one of the most serious pests of irrigated rice. The damage caused by $\mathrm{BPH}$ feeding has a major effect on crop growth and yield (Watanabe and Kitagawa, 2000; Yuan et al. 2005). BPH not only feeds on the rice plant directly but also transmits 
viruses that cause severe diseases (Heinrichs 1979). The use of $\mathrm{BPH}$ resistance genes has been recognized as the most economic, effective and environmentally friendly solution to this problem. The stability of BPH resistance in Rathu Heenati (RH), a traditional Sri Lankan rice cultivar containing qBph3, has made this strain one of the most popular hopper-resistance donors in the Mekong subregion, where rice production is highly intensive. QTL mapping located qBph3 to the short arm of chromosome 6 between RM589 and RM588 based on KDML105 × Rathu Heenati (Jairin et al. 2009) and PTB33 $\times$ RD6 (Jairin et al. 2007) crossings. Other BPH resistance QTLs have also been reported, including Bph17 on chromosome 4 (Sun et al. 2005), Bph4 on chromosome 6 (Kawaguchi et al. 2001; Sun et al. 2006) and Bph18 on chromosome 12 (Jena et al. 2006). In addition to resistance QTLs, a putative sesquiterpene synthase (TPS) gene (Os04g27430) was identified using SFP mapping with isogenic lines derived from the backcross of RH and KDML105 (Kamolsukyunyong et al. 2013). The TPS gene is induced after 5 days of $\mathrm{BPH}$ feeding. Functional markers were identified in exon 5 of the TPS gene that resulted in the deletion of seven amino acids in the susceptible rice line, as well as three additional SNPs associated with a transcriptional binding site, accounting for the differential response of TPS during the anti-feeding test (Kamolsukyunyong et al. 2013).

Alkali disintegration has been used as a biomarker for gelatinization temperature $(\mathrm{GT})$ in rice (Waters et al. 2006; Kate-ngam et al. 2008; Masouleh et al. 2012). The alkali disintegration locus $(A L K)$ was identified as the starch synthase IIa (SSIIa) gene on chromosome 6 that determines amylopectin structure (Bao et al. 2004; Bao et al. 2006a; Umemoto et al. 2002; Umemoto et al. 2004; Umemoto and Aoki, 2005; Waters et al. 2006; Lu et al. 2010). Two functional SNPs were identified: GC/TT and G/A at positions 4329/4330 bp and 4198 bp, respectively (accession AY423717) (Bao et al. 2006b; Umemoto et al. 2002; Umemoto et al. 2004; Umemoto and Aoki, 2005; Waters et al. 2006; Lu et al. 2010). Successful marker assisted selection (MAS) programs utilizing the GT haplotypes for improving starch profiles have been reported (Tian et al. 2009; Lu et al. 2010).

'PinK3' is an aromatic, high-yielding, non-photoperiodsensitive, high-amylose rice variety, but it is susceptible to $\mathrm{BPH}, \mathrm{BB}, \mathrm{BL}$ and Sub stresses. Here, we report the successful gene/QTL pyramiding of five functional genes (xa5, Xa21, Sub1A-C, SSIIa, TPS) and three QTLs (qBph3, qBL1, qBL11) into the 'PinK3' genome background using a multiplex pseudo-backcrossing approach based on MAS. The new, improved lines have a high-yield phenotype that confers submergence tolerance and resistance to $\mathrm{BPH}, \mathrm{BB}$ and BL. This is the first report describing the application of pseudo-backcrossing to significantly shorten the time required for gene/QTL pyramiding in an annual crop (rice).

\section{Results}

\section{Streamline gene pyramiding in rice}

Four sets of donors (Table 1) containing a set of target genes/QTLs-Cholsub (Sub1A-C and SSIIa), Xa497 (xa5 and Xa21), Bph162 (qBph3 and TPS), and RBPiQ (qBL1 and qBL11) - were backcrossed in parallel once to 'PinK3' by targeting $\mathrm{MAB}$ to generate four sets of $\mathrm{BC}_{1} \mathrm{~F}_{1}$ progeny. The resulting $\mathrm{BC}_{1} \mathrm{~F}_{1}$ progeny were stepwise crossed to recombine four sets of the target genes/QTLs into a single set of pseudo-backcrossed progenies. By pair-wise crossing two pairs of $\mathrm{BC}_{1} \mathrm{~F}_{1}$ lines, two sets of pseudo-backcrossed progeny- $\mathrm{BC}_{2} \mathrm{~F}_{1}$ (Sub1A-C, SSIIa, xa5 and Xa21) and $\mathrm{BC}_{2} \mathrm{~F}_{1}$ (qBph3, TPS, qBL1 and qBL11) - were generated (Figure 1). In cycle 4, all target genes/QTLs (Sub1A-C, SSIIa, xa5, Xa21, TPS, qBph3, qBL1 and qBL11) were recombined by crossing the two pseudo-backcrossed $\mathrm{BC}_{2} \mathrm{~F}_{1}$ lines to generate 2,630 pseudo-backcrossed $\mathrm{BC}_{3} \mathrm{~F}_{1}$ progeny. Using target MAS and plant-type selection, 158 fully heterozygous pseudo-backcrossed $\mathrm{BC}_{3} \mathrm{~F}_{1}$ lines were selected and selfed (cycle 5) to generate 11,405 $\mathrm{F}_{2}$ progeny for large-scale, full-target MAS to generate 29 families for the target MAS purification. The numbers of positive plants (pseudo $\mathrm{BC}_{3} \mathrm{~F}_{2}$ ) for all target genes/QTLs were segregated with Mendelian pattern (homozygous preference genotype $\left.=1 / 4^{\mathrm{n}}\right)$. In cycle 6 , selfing and full-target MAS yielded 29 best-selected, fully homozygous pseudobackcrossed inbred lines (pseudo-BILs) carrying positive homozygous alleles of all of the donor genes, including Sub1A-C, SSIIa, xa5, Xa21, and TPS as well as qBph3 and qBL1-qBL11.

Of these lines, five pseudo- $\mathrm{BC}_{3} \mathrm{~F}_{3}$ BILs were chosen for field evaluation. The five pseudo $\mathrm{BC}_{3} \mathrm{~F}_{3} \mathrm{BILs}(\mathrm{PinK}+4)$ were selected based on completion of the target genomic regions with interesting starch profiles suitable for glycemic index research in the future (data not shown). In total, four donors and one recipient were intensively crossed and selected for seven cycles: two cycles to generate $\mathrm{BC}_{1} \mathrm{~F}_{1}$, another two cycles to generate pseudobackcrossed $\mathrm{BC}_{3} \mathrm{~F}_{1}$, and three cycles of selfing to fix the final best-selected pseudo- $\mathrm{BC}_{3} \mathrm{~F}_{3} \mathrm{BIL}$ for field evaluation.

\section{Graphical genotyping of pseudo-BIL}

To determine the effects of pseudo-backcrossing on genomic background composition, nine elite pseudo-BIL $\left(\mathrm{BC}_{3} \mathrm{~F}_{2}\right)$ families were selected for genome scanning using 61 SSRs, 35 and 26 of which were located on six carrier and six non-carrier chromosomes, respectively (Additional file 1). The whole genome composition of the selected pseudo-BILs was characterized as the percentages of recurrent genome content (\%RGC) and donor genome content (\%DGC) based on the physical intervals of the SSR-based genome scanning using five $\mathrm{BC}_{1} \mathrm{~F}_{2}$ (Table 2 and Additional file 2), two $\mathrm{BC}_{2} \mathrm{~F}_{2}$ (data not shown) and nine pseudo- $\mathrm{BC}_{3} \mathrm{~F}_{3}$ BILs (Table 3 and 
Table 1 The four donors and recurrent parents used in the multiple backcross gene pyramiding

\begin{tabular}{|c|c|c|c|c|c|c|c|c|c|c|c|c|c|c|c|}
\hline \multirow{2}{*}{$\begin{array}{l}\text { Cultivar/breeding } \\
\text { line }\end{array}$} & \multirow[t]{2}{*}{ Description } & \multirow{2}{*}{$\begin{array}{l}\text { Variety } \\
\text { type }\end{array}$} & \multirow[t]{2}{*}{ Cross } & \multicolumn{11}{|c|}{ Genotype on carrier chromosomes and target gene (s) or QTLs } & \multirow[t]{2}{*}{ References } \\
\hline & & & & Sub & $x a 5$ & Xa21 & qBL1 & qBL11 & Bph3 & TPS & $W x$ & SSiia & Os2AP & Hd1 & \\
\hline PinK3 & $\begin{array}{l}\text { High yielding aromatic rice } \\
\text { (pseudo-recurrent parent) }\end{array}$ & RIL & IR71501/(KDMl105/CT9993) & - & - & - & - & - & + & - & + & - & + & + & Rice Science Center (unpublished) \\
\hline Cholsub1 & $\begin{array}{l}\text { Submergence tolerance } \\
\text { aromatic rice with high GT }\end{array}$ & RIL & IR57514/KDMl105 & + & - & - & - & - & - & - & - & + & + & + & Jantaboon et al. 2011 \\
\hline Xa497 & BLB resistance aromatic rice & $\mathrm{BC}_{2} \mathrm{~F}_{2}$ & IR62266/KDMI105 & - & + & + & - & - & - & - & - & - & + & + & Korinsak 2009 \\
\hline RBPiQ & Blast resistance & RIL & $\mathrm{JHN} / \mathrm{KDMl} 105$ & - & - & - & + & + & - & - & - & - & - & + & Rice Science Center (unpublished) \\
\hline Bph162 & $\begin{array}{l}\text { Bph resistance } \\
\text { photosensitive rice }\end{array}$ & $\mathrm{BC}_{3} \mathrm{~F}_{6}$ & Rathu Heenati/KDMl105 & - & - & - & - & - & + & + & - & - & - & - & Jairin et al. 2009 \\
\hline
\end{tabular}

$+=$ desirable allele.

= undesirable allele. 


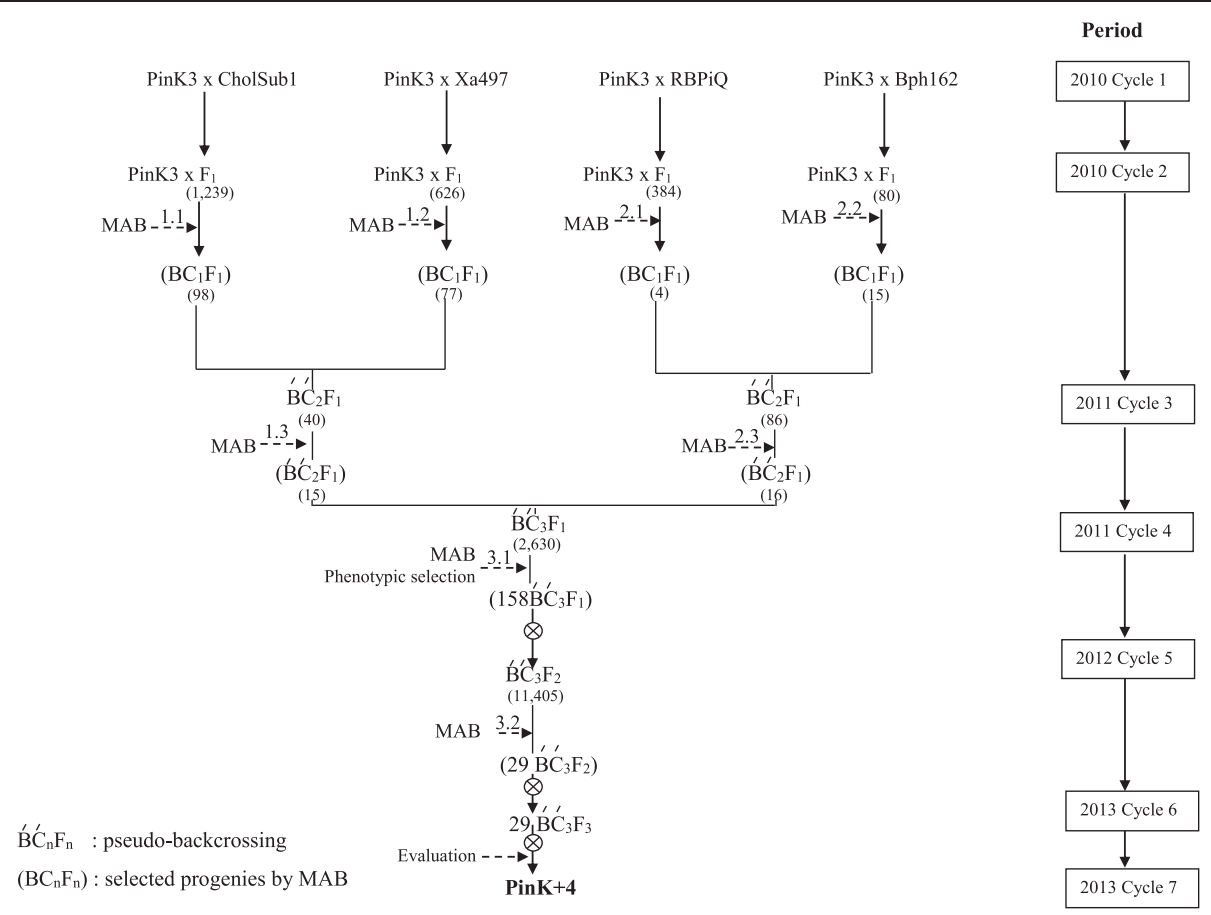

Figure 1 The gene/QTL pyramiding scheme used to generate the high-yield pseudo-BC BIL'PinK +4 ' line exhibiting submergence tolerance $(S u b 1 A-C)$, bacterial leaf blight resistance (Xa21, xa5), rice blast resistance ( $q B L 1$ and $q B L 11$ ), brown planthopper resistance ( $q B p h 3$ and TPS) and desired cooking qualities $(W x, S S I l a, O s 2 A P)$.

Table 2 The percentage of genome composition (average per target locus) of the selected $\mathrm{BC}_{1} \mathrm{~F}_{2}$ lines resulting from backcrossing of four donors: CholSub1, Xa497, RBPiQ, and Bph162 on PinK3

\begin{tabular}{|c|c|c|c|c|c|c|c|c|c|}
\hline & \multicolumn{8}{|c|}{ \% genome compositions (average per donor) } & \multirow{3}{*}{ Sum } \\
\hline & \multirow{2}{*}{$\begin{array}{l}\text { CholSub } \\
\text { Sub1 }\end{array}$} & \multicolumn{2}{|c|}{ Xa497 } & \multicolumn{2}{|l|}{ RBPiQ } & \multicolumn{2}{|c|}{ qBph162 } & \multirow[t]{2}{*}{ Ave. } & \\
\hline & & $x a 5$ & $X a 21$ & qBL1 & qBL11 & TPS & qBph3 & & \\
\hline Target gene/QTL & $<0.01$ & $<0.01$ & $<0.01$ & 0.03 & 0.26 & $<0.01$ & 0.05 & 0.09 & 0.34 \\
\hline Donor segment link & 1.81 & 0.00 & 3.77 & 1.59 & 0.00 & 0.00 & 0.00 & 1.79 & 7.17 \\
\hline Heterozygous segment link ${ }^{1 /}$ & 0.00 & 0.83 & 0.13 & 0.12 & 0.95 & 0.00 & 1.16 & 0.80 & 3.19 \\
\hline Donor segment unlink & 0.00 & 0.00 & 1.03 & 0.00 & 0.00 & 2.60 & 0.00 & 0.91 & 3.63 \\
\hline Heterozygous segment unlink ${ }^{1 /}$ & 0.00 & 0.00 & 0.52 & 0.40 & 1.61 & 0.00 & 0.00 & 0.63 & 2.53 \\
\hline Sum of donor segments on target carrier chromosome & 1.81 & 0.83 & 5.45 & 2.14 & 2.82 & 2.6 & 1.21 & 4.22 & 16.86 \\
\hline \multicolumn{4}{|l|}{ Donor segments on non-target carrier chromosome $(4-5 \mathrm{ch})$} & & & & & 7.71 & \\
\hline \multicolumn{4}{|c|}{${ }^{1 / H e t e r o z y g o u s ~ s e g m e n t s ~ o n ~ n o n-t a r g e t ~ c a r r i e r ~ c h r o m o s o m e ~(4-5 c h) ~}$} & & & & & 1.96 & \\
\hline \multicolumn{4}{|l|}{ Sum of donor segments on non-target carrier chromosome } & & & & & 13.89 & \\
\hline \multicolumn{4}{|l|}{ Donor segments on non-carrier chromosome (6 ch) } & & & & & 4.29 & \\
\hline \multicolumn{4}{|l|}{${ }^{1 / H e t e r o z y g o u s ~ s e g m e n t s ~ o n ~ n o n-c a r r i e r ~ c h r o m o s o m e ~}$} & & & & & 1.78 & \\
\hline \multicolumn{4}{|l|}{ Sum of donor segments on non-carrier chromosome } & & & & & 6.07 & \\
\hline \multicolumn{2}{|l|}{ Recurrent background } & & & & & & & 74.87 & \\
\hline \multicolumn{2}{|l|}{$\%$ RGC } & & & & & & & 80.04 & \\
\hline \multicolumn{2}{|l|}{$\% D G C$} & & & & & & & 19.96 & \\
\hline
\end{tabular}

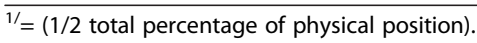


Table 3 The percentage genome compositions (average per target locus) in nine selected pseudo-BC $\mathrm{F}_{3} B \mathrm{BILS}$

\begin{tabular}{|c|c|c|c|c|c|c|c|}
\hline \multirow[t]{2}{*}{ Region } & \multicolumn{7}{|c|}{$\%$ genome compositions (average per target) } \\
\hline & Sub & $x a 5$ & qBL1 & Xa21_qBL11 ${ }^{1 /}$ & TPS & qBph3_SSIII' & Sum \\
\hline Target gene/QTL & $<0.01$ & $<0.01$ & 0.03 & 0.26 & $<0.01$ & 0.05 & 0.34 \\
\hline Donor segment link & 1.61 & 1.22 & 1.55 & 2.11 & 0.19 & 0.00 & 6.68 \\
\hline Heterozygous segment link & 0.54 & 0.83 & 0.24 & 0.24 & 0.00 & 0.00 & 1.85 \\
\hline Donor segment unlink & 0.00 & 0.18 & 1.39 & 1.40 & 1.44 & 0.47 & 4.88 \\
\hline Heterozygous segment unlink & 0.00 & 0.00 & 0.04 & 0.23 & 0.00 & 0.76 & 1.03 \\
\hline Sum of donor segments on target carrier chromosome & 2.15 & 2.23 & 3.25 & 4.24 & 1.63 & 1.28 & 14.78 \\
\hline Donor segments on non-carrier chromosome (6ch) & & & & & & & 5.03 \\
\hline Heterozygous segments on non-carrier chromosome (6ch) & & & & & & & 2.71 \\
\hline Sum of donor segments on non-carrier chromosome & & & & & & & 7.74 \\
\hline Recurrent background & & & & & & & 71.89 \\
\hline$\%$ RGC & & & & & & & 77.48 \\
\hline$\%$ DGC & & & & & & & 22.52 \\
\hline
\end{tabular}

${ }^{1 / X a 21}$ located within qBL11 on chromosome 11.

${ }^{2 /}$ SSIla located within qBph3 on chromosome 6.

Additional file 3). The \%RGC and \%DGC of $\mathrm{BC}_{1} \mathrm{~F}_{2}$ ranged from 69.99 to $88.98 \%$ and from 11.02 to $30.01 \%$, respectively (Additional file 2), whereas those variables for the pseudo- $\mathrm{BC}_{3} \mathrm{~F}_{3} \mathrm{BILs}$ ranged from 74.50 to $81.30 \%$ and 18.70 to $25.50 \%$, respectively (Additional file 3 ). The mean \% RGC and \%DGC values for $\mathrm{BC}_{1} \mathrm{~F}_{2}$ were $80.04 \%$ and $19.96 \%$, respectively (Table 2), whereas these values for the pseudo-BC $\mathrm{B}_{3} \mathrm{~F}_{3} \mathrm{BILs}$ were $77.48 \%$ and $22.52 \%$, respectively (Table 3 ). These results indicated that at the $\mathrm{BC}_{1} \mathrm{~F}_{1}$ step, there were no significant gains or losses of $\%$ RGC and \%DGC from the two cycles of pseudobackcrossing. For this reason, the theoretical RGC in pseudo- $\mathrm{BC}_{3} \mathrm{~F}_{3}$ was not met.

We then looked into the distribution of donor genome segments across the six carrier and non-carrier chromosomes. For the carrier chromosomes, linkage drags were identified upstream and/or downstream of the donated target gene/QTL following transmission to the recipient genome. Even considering the stringent $\mathrm{MAB}$ on all target genes/QTLs during the $\mathrm{BC}_{1}$ cycle, linkage drags were still detected for almost every donated locus, both homozygous and heterozygous, on one or both sides of the target gene/QTL, constituting more than half of the total donor segments on the carrier chromosomes (Table 2). The largest linkage drags were detected on both sides of the Xa21 locus (Table 2). However, only a small heterozygous linkage drag was detected at the xa5 locus. The contrast between the degree of linkage drag for the two functional genes $\mathrm{Xa21}$ and $x a 5$ was unexpected, as the pair of loci was inherited from the same donor, Xa497. As both $x a 5$ and Xa21 were MAB using their functional markers, it is interesting to speculate on the differences in linkage drag between the two functional genes. The size of the linkage of Xa21 is much greater than for the two functional genes Sub1 and TPS, and the other QTLs, qBL1, qBL11 and qBph3. Heterozygous linkage drags were identified for five of the eight target genes/QTLs, including the $\mathrm{Xa21}$ locus (Table 2), Donor-unlinks-the additional donor segments co-transmitted on the opposite (unlinked) chromosome arms of the target genes/QTLs-were identified on the carrier chromosomes containing Xa21, qBL1, qBL11 and TPS (Table 2). Therefore, the total donor segments transmitted via $\mathrm{BC}_{1}$ along with $\mathrm{Xa21}$ were obviously the largest among the target loci under MAB (Table 2).

Multiple target loci from donors are combined in the recipient genome, which include both linkage and nonlinkage drags on the carrier chromosomes. Following two successive cycles of marker-assisted pseudo-backcrossing, $\mathrm{BC}_{3} \mathrm{~F}_{3} \mathrm{BILs}$ linkage drags were detected innearly every case, with the exception of the qBph3-SSIIa locus. The total linkage drag (combined homozygous and heterozygous types) was $8.53 \%$, which is more than half of the total donor component on carrier chromosomes (Table 3). The unlinkage drag values of the donated segments on the carrier chromosomes were between 5.91 and $40 \%$ of the total donor component on the carrier chromosomes (Table 3). To trace the potential origins of these large donor components, the sum of all donor compositions in the selected $\mathrm{BC}_{1} \mathrm{~F}_{2}$ lines was compared with those components in the selected $\mathrm{BC}_{3} \mathrm{~F}_{3} \mathrm{BILs}$. On average, the donor genome content in $\mathrm{BC}_{3} \mathrm{~F}_{3} \mathrm{BILs}$ was not significantly different from that of $\mathrm{BC}_{1} \mathrm{~F}_{2}$ (Table 2 and Table 3). The same was true for the homozygous components of linkage drag and donor unlinked, whereas the heterozygous components were significantly decreased during pseudo-backcrossing. These results could indicate that high frequency of recombination between donated segments and the recipient 
genome contents of the carrier chromosomes in the $\mathrm{BC}_{1}$ cycle was primarily due to the high donor genome content in successive pseudo-backcrossings. Furthermore, the significant reduction in heterozygous donor components for the $\mathrm{BC}_{3} \mathrm{~F}_{3} \mathrm{BILs}$ highlights an advantage of pseudo-backcrossing in gene pyramiding.

For the non-carrier chromosomes, the total donor components on all six non-carrier chromosomes were not significantly affected (Table 2 and Table 3 ). However, the heterozygous donor components on both carrier and non-carrier chromosomes persisted, even in the selected pseudo-backcrossed $\mathrm{BC}_{3} \mathrm{~F}_{3} \mathrm{BILs}$. These results show that pseudo-backcrossing has similar effects as conventional backcrossing when considering the recovery of the genome content on non-carrier chromosomes.

\section{Evaluation of the PinK +4 phenotype}

Field evaluations of agronomic and grain quality were performed based on complete target genes/QTLs, plant types, days to harvest and grain quality. The foreground selection successfully fixed homozygosity of the five target genes (Sub1A-C, SSIIa, xa5, Xa21 and TPS) and three QTLs for BL and BPH into approximately $77 \%$ of the genetic background of the pseudo-recurrent parent 'PinK3' (Table 3 and Additional file 3). However, the majority of the advanced progeny exhibited significant phenotypic variation from their pseudo-recurrent parent 'PinK3' with respect to nearly all evaluated traits, with the exception of amylose content, grain length per width ratio and polished grain length (Tables 4 and 5).
The uniformity of the pseudo- $\mathrm{BC}_{3} \mathrm{~F}_{3} \mathrm{BILs}$ was the result of MAS. Even with respect to complex traits, such as grain yield, some of these progeny performed as well as the pseudo-recurrent parent 'PinK3' and significantly outperformed their donors (Table 4 and Figure 2). However, some progeny inherited inferior characteristics from the resistance donors, which affected maturity, grain numbers per panicle (NGP), \% seed fertility (PSF) and grain yield (GY). In all cases, early-maturing progeny produced a lower grain number per panicle and lower grain yield (Table 4). Therefore, without rigorous background selection, pseudo-backcrossed progeny may not possess the desirable characteristics of their pseudo-recurrent parent.

For the Sub1 selection, all progeny exhibited a significantly improved ability to withstand flash flooding during seedling stages compared with the susceptible 'PinK3' (Table 4). However, significant phenotypic variation (3156\%) was observed among the Sub1-Pink3 families compared with the control phenotype. Two reasons for this variation; First, the Sub1 gene was not directly inherited from the original FR13A but from CholSub1 donor one of the RILs from the mapping pop 'KD $\times$ FR13A' (IR57514) for submergence tolerance QTL by Siangliw et al. (2003). The second reason is the quantitative nature of multiple gene/QTL may partially regulated by recipient genetic background of CholSub1 donor and the 'PinK3', the highly susceptible recipient. Furthermore, the fact that significant variations in traits related to submergence tolerance were observed among the individual progeny of IR57514/Kao Dawk Mali 105 (Jantaboon et al. 2011) is also consistent

Table 4 Trait evaluation and agronomic characteristics of four selected pseudo- $\mathrm{BC}_{3} \mathrm{~F}_{3} \mathrm{BILs}(\mathrm{PinK}+4)$ and parental lines with respect to submergence, bacterial blight, brown planthopper and blast resistance

\begin{tabular}{|c|c|c|c|c|c|c|c|c|c|c|c|c|c|}
\hline \multirow[t]{2}{*}{ No } & \multirow[t]{2}{*}{ Name } & \multirow[t]{2}{*}{ Family } & \multicolumn{4}{|c|}{ Trait evaluation $^{1 /}$} & \multicolumn{7}{|c|}{ Agronomic characteristics $^{2 /}$} \\
\hline & & & Sub & BLB (TX0156) & Bph(UBN) & Blast (Mixed\#2) & $\mathrm{DM}$ & NTP & $\mathrm{PH}(\mathrm{cm})$ & NGP & PSF (\%) & TGW (g) & GY (kg/ha) \\
\hline 1 & 1E_06 & 1_H06 & $50.7^{\mathrm{c3/}}$ & $1.5^{\mathrm{a}}$ & $1.7^{a}$ & $0.7^{a}$ & $140.0^{\mathrm{e}}$ & $9.3^{a b}$ & $70.1^{\mathrm{bc}}$ & $276.7^{e}$ & $82.5^{\mathrm{ef}}$ & $42.9^{f}$ & $7777^{\mathrm{ef}}$ \\
\hline 2 & $20 A 09$ & 4_E02 & $42.0^{\mathrm{bc}}$ & $1.4^{\mathrm{a}}$ & $1.7^{\mathrm{a}}$ & $0.7^{\mathrm{a}}$ & $140.0^{e}$ & $9.3^{a b}$ & $79.0^{c}$ & $224.3^{d}$ & $69.6^{c}$ & $41.4^{\mathrm{e}}$ & $7381^{\text {ef }}$ \\
\hline 3 & $66 B 09$ & 3_E03 & $31.3^{b}$ & $0.8^{\mathrm{a}}$ & $1.7^{\mathrm{a}}$ & $0.6^{a}$ & $128.0^{c}$ & $9.2^{a b}$ & $77.7^{c}$ & $236.1^{d}$ & $76.1^{d}$ & $42.5^{f}$ & $6977^{\text {de }}$ \\
\hline 4 & 78A03 & 13_H06 & $52.0^{c}$ & $0.8^{a}$ & $3.7^{\mathrm{abc}}$ & $0.0^{\mathrm{a}}$ & $143.0^{h}$ & $9.2^{a b}$ & $78.3^{c}$ & $241.0^{d}$ & $77.3^{d}$ & $42.4^{f}$ & $6966^{\text {de }}$ \\
\hline 5 & 117A08 & 2_A10 & $56.0^{c}$ & $1.5^{\mathrm{a}}$ & $3.0^{a b}$ & $0.0^{a}$ & $126.0^{c}$ & $8.6^{a}$ & $77.3^{c}$ & $168.7^{c}$ & $81.1^{\mathrm{e}}$ & $41.5^{e}$ & $6175^{c d}$ \\
\hline 6 & PinK3 & recurrent & $0.0^{a}$ & $12.8^{b}$ & $6.3^{\mathrm{cd}}$ & $5.7^{d}$ & $141.3^{f}$ & $8.3^{a}$ & $77.0^{c}$ & $301.0^{f}$ & $62.0^{b}$ & $40.3^{d}$ & $8306^{f}$ \\
\hline 7 & Xa497 & donor & $3.3^{\mathrm{a}}$ & $0.5^{a}$ & $6.3^{\mathrm{cd}}$ & $3.7^{c}$ & $134.0^{d}$ & $9.5^{\mathrm{ab}}$ & $59.3^{a}$ & $166.0^{c}$ & $84.9^{f}$ & $40.5^{d}$ & $5417^{c}$ \\
\hline 8 & Cholsub1 & donor & $50.7^{c}$ & nd & $5.7^{b c}$ & $2.3^{b}$ & $122.0^{b}$ & $10.7^{b c}$ & $62.7^{a b}$ & $120.3^{b}$ & $75.0^{\mathrm{d}}$ & $39.4^{c}$ & $4041^{b}$ \\
\hline 9 & RBPiQ & donor & $2.0^{\mathrm{a}}$ & $18.4^{b}$ & $9.0^{d}$ & $0.0^{a}$ & $142.0^{9}$ & $10.4^{\mathrm{cd}}$ & $74.3^{c}$ & $185.7^{c}$ & $94.1^{9}$ & $34.8^{\mathrm{a}}$ & $5581^{c}$ \\
\hline 10 & Bph162 & donor & $0.0^{\mathrm{a}}$ & $15.6^{\mathrm{b}}$ & $1.0^{\mathrm{a}}$ & $3.3^{c}$ & $99.0^{\mathrm{a}}$ & $12.8^{\mathrm{d}}$ & $69.7^{\mathrm{bc}}$ & $81.0^{\mathrm{a}}$ & $58.5^{\mathrm{a}}$ & $38.5^{\mathrm{b}}$ & $2227^{\mathrm{a}}$ \\
\hline
\end{tabular}

\section{Remarks:}

${ }^{1 /}$ Trait evaluation.

Sub $=$ Average $\%$ plant survival (\%PS) after 15 days of flash flooding.

$\mathrm{BLB}=$ average lesion length in centimeters of the damage caused by the BB isolate TXO156.

$\mathrm{Bph}=$ Severity scores with UBN biotype at 9 DAI when TN1, the susceptible control died.

Blast $=$ Average blast injury score when attacked by a Mixed\#2 blast isolate from Thailand

${ }^{2 /}$ Agronomic characteristics.

DM (days to maturity), NTP (number of tillers per plant), PH (plant height from the soil surface to the neck of the panicle), NGP (number of grains per panicle), PSF (percent spikelet fertility), TGW (1,000 grain weight) and GY (grain yield).

${ }^{3 /}$ Average values marked with different letters in the same column are significantly different at the $95 \%$ confidence level using LSD. 
Table 5 Grain quality and cooking quality traits of five pseudo-BC $\mathrm{F}_{3} \mathrm{BILs}(\mathrm{PinK}+4)$ as well as the donor and recurrent parents

\begin{tabular}{|c|c|c|c|c|c|c|c|c|}
\hline No. & Name & $\mathrm{BR}^{1 /}(\%)$ & $\mathrm{HR}^{1 /}(\%)$ & $\mathrm{GL} / \mathrm{W}^{1 /}$ & $\mathrm{PRL}^{1 /}(\mathrm{mm})$ & $\mathrm{AC}^{1 /}(\%)$ & $\mathrm{ASV}^{1 /}$ & $\mathrm{CE}^{1 /}(\%)$ \\
\hline 1 & 1E_06 & $72.9^{c 2}$ & $51.8^{c}$ & $3.0^{\mathrm{ns}}$ & $0.75^{\text {ns }}$ & $29.3^{c}$ & $7.0^{c}$ & $36.7^{\mathrm{abc}}$ \\
\hline 2 & $20 A 09$ & $72.9^{c}$ & $52.7^{c}$ & $3.1^{\text {ns }}$ & $0.74^{\mathrm{ns}}$ & $27.6^{c}$ & $7.0^{c}$ & $43.3^{\text {cdef }}$ \\
\hline 3 & 66B09 & $71.5^{\mathrm{b}}$ & $52.1^{c}$ & $3.1^{\mathrm{ns}}$ & $0.76^{\mathrm{ns}}$ & $27.5^{c}$ & $2.0^{\mathrm{a}}$ & $31.5^{\mathrm{a}}$ \\
\hline 4 & $78 \mathrm{~A} 03$ & $71.2^{\mathrm{b}}$ & $51.3^{c}$ & $3.2^{\text {ns }}$ & $0.78^{\text {ns }}$ & $27.1^{c}$ & $2.0^{\mathrm{a}}$ & $31.2^{\mathrm{a}}$ \\
\hline 5 & $117 \mathrm{~A} 08$ & $73.0^{c}$ & $53.1^{c}$ & $2.9^{\mathrm{ns}}$ & $0.73^{\mathrm{ns}}$ & $29.5^{c}$ & $7.0^{c}$ & $46.7^{\mathrm{ef}}$ \\
\hline 6 & PinK3 & $72.4 b^{c}$ & $43.4^{b}$ & $3.1^{\mathrm{ns}}$ & $0.74^{\mathrm{ns}}$ & $29.2^{c}$ & $7.0^{c}$ & $39.4^{\mathrm{bcd}}$ \\
\hline 7 & Xa497 & $71.9 b^{c}$ & $53.3^{c}$ & $3.4^{\mathrm{ns}}$ & $0.74^{\mathrm{ns}}$ & $22.0^{\mathrm{b}}$ & $5.0^{\mathrm{b}}$ & $40.3^{\text {bcde }}$ \\
\hline 8 & Cholsub & $73.2^{c}$ & $42.4^{b}$ & $3.4^{\mathrm{ns}}$ & $0.74^{\text {ns }}$ & $14.5^{\mathrm{a}}$ & $2.0^{\mathrm{a}}$ & $44.4^{\mathrm{def}}$ \\
\hline 9 & RBPiQ & $71.0^{\mathrm{b}}$ & $41.3^{b}$ & $3.4^{\mathrm{ns}}$ & $0.68^{\text {ns }}$ & $14.2^{\mathrm{a}}$ & $5.0^{\mathrm{b}}$ & $35.9^{\mathrm{ab}}$ \\
\hline 10 & Bph162 & $68.6^{a}$ & $30.2^{\mathrm{a}}$ & $3.2^{\text {ns }}$ & $0.70^{\text {ns }}$ & $14.0^{\mathrm{a}}$ & $5.0^{\mathrm{b}}$ & $48.6^{f}$ \\
\hline
\end{tabular}

Remarks: ${ }^{1 / B R}$ (brown rice), HR (head rice), GL/W (grain length-width ratio), PRL (polished rice length), AC (amylose content), ASV (alkaline spreading value (1.7\% $\mathrm{KOH})$ ), and $\mathrm{CE}$ (cooking elongation).

${ }^{2 /}$ Average values marked with different letters in the same column are significantly different at the $95 \%$ confidence level using LSD.

Rice grains were harvested from the yield trial field during the wet season of 2012/2013.

with our findings, indicating the quantitative nature of such traits.

For $\mathrm{BB}$, selection based on $x a 5$ and $\mathrm{Xa21}$ resulted in significant improvements in bacterial leaf blight resistance, specifically to the TXO156 virulent isolate (Table 4) and to several $\mathrm{BB}$ isolates identified in Thailand (Additional file 4). For leaf/neck blast resistance, QTL pyramiding of the two QTLs on chromosomes 1 and 11 onto the 'PinK3' background successfully improved resistance to a wide range of blast isolates collected in Thailand (Table 4).
For $\mathrm{BPH}$ resistance, based on the UBN biotype (a $\mathrm{BPH}$ biotype that has been well characterized in Thailand), the progeny exhibited significant improvement over their pseudo-recurrent parent 'PinK3' but were not as resistant as the resistance donor. The Bph3 QTL and the TPS gene from the Bph162 donor were co-inherited from the broad spectrum BPH resistance cultivar 'Rathu Heenati' in crosses with KDML105, as reported by Jairin et al. (2009). Some selected introgression lines from that report were moderately resistant (MR) to various $\mathrm{BPH}$
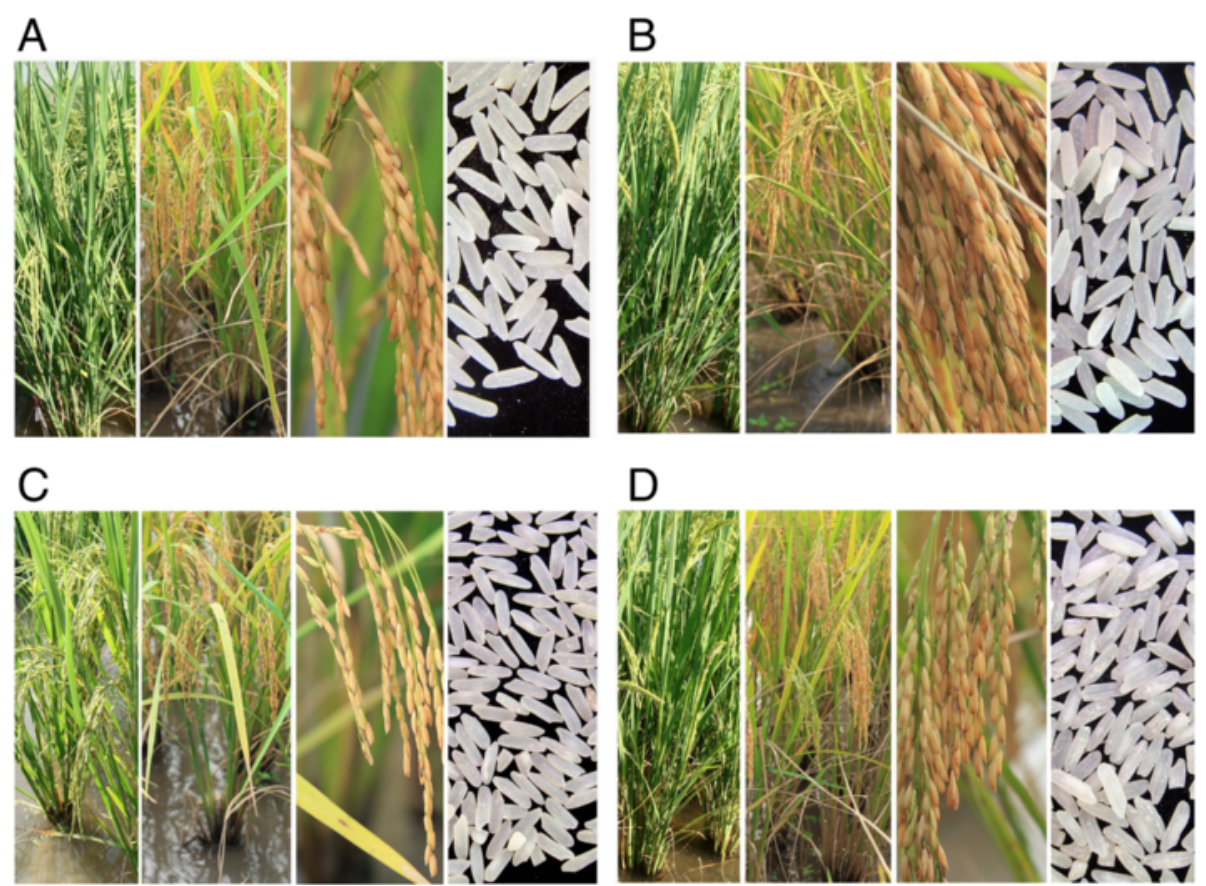

D

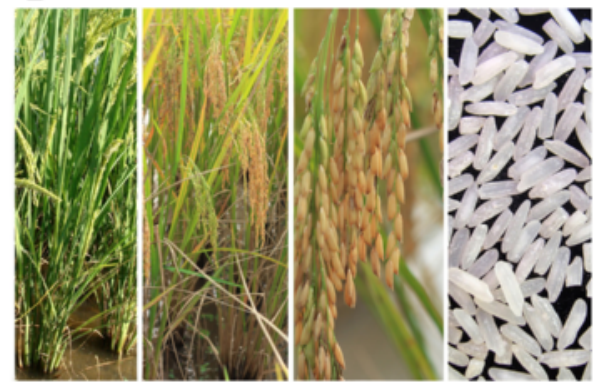

Figure 2 Plant and grain types of pseudo-BC BIL PinK + 4 compared with PinK3 (pseudo-recurrent parent). A) PinK $+4 \# 1 E 06$, B) PinK + 4\#20A09, C) PinK + 4\#66B09 and D) PinK3. 
biotypes. It appears that introgression of only qBph3 and TPS from Bph162 in pseudo-backcrossed BILs was not enough to withstand some of the $\mathrm{BPH}$ biotypes used in our experiments.

All selected pseudo- $\mathrm{BC}_{3} \mathrm{~F}_{3}$ BILs $(\mathrm{PinK}+4)$ contained the aromatic allele and the $W x^{a}$ allele known to confer high amylose content and a starch profile suitable for further analysis and industrial food applications.

\section{Discussion}

\section{Streamline backcrossing design}

In a gene-pyramiding project, several donors, each providing a target QTL with flanking markers, are used as parental sources for new traits with the goal of improving a favorable variety that has a preferred genetic background. To best facilitate the efficient integration of multiple QTLs into a single optimal variety, an improved breeding platform was developed based on pseudobackcrossing. In conventional backcross breeding experiments, nearly isogenic lines from each donor were developed prior to pyramiding (Luo and Yin, 2013; Singh et al. 2013) to recover the background genome of the recurrent parent. However, when introducing multiple traits, this approach can be tedious and time-consuming. This novel platform based on pseudo-backcross breeding involves both multiple foreground selection and background genome recovery in an abridged manner. Within seven cycles-consisting of a single backcross, two cycles of pseudo-backcrossing and three cycles of line fixationthe entire project was accomplished within four years.

\section{Recurrent genome background recovery}

Transferring multiple resistance genes using conventional $\mathrm{MAB}$ requires at least three to four backcrosses to guarantee a high recovery of the recurrent parent phenotype (Joshi and Nayak, 2010; Suh et al. 2013). In this study, without background selection, the pseudo- $\mathrm{BC}_{3} \mathrm{~F}_{3} \mathrm{BILs}$ $($ PinK +4$)$ contained 74.50 to $81.30 \%$ RGC, which is significantly below the theoretical value of $93.75 \%$ possible following three conventional backcrossings. When comparing graphical genotyping among $\mathrm{BC}_{1} \mathrm{~F}_{2}$ progeny and pseudo- $\mathrm{BC}_{3} \mathrm{~F}_{3} \mathrm{BILs}$, the total \%DGC was only slightly increased. These results indicate that without background selection, pseudo-backcrossing can only maintain the \% RGC gained during the first backcross generation. A low background recovery rate was also reported for the introgression of stripe rust resistance in wheat. Without marker-assisted background selection, the \%RGC was only $82 \%$ in $\mathrm{BC}_{4} \mathrm{~F}_{7}$ progeny (Randhawa et al. 2009). However, when combined with phenotypic selection, \%RGC was improved to $85-92 \%$ in $\mathrm{BC}_{3}$ (Sundaram et al. 2008; Korinsak et al. 2011; Singh et al. 2013). Indeed, the utilization of genome-wide molecular markers for background screening during backcrossing has been suggested as the best method for improving low \%RGC (Rajpurohit et al. 2011; Suh et al. 2013).

The number of molecular markers used for genomewide scanning, which ultimately determines cost vs. precision, has varied from 44 to 205 SSR loci in rice. Four groups have reported rice MAB projects involving background selection: Group 1) used 44-51 SSRs (Yi et al. 2009; Siangliw et al. 2003; Tomita 2009; Wongsaprom et al. 2010), Group 2 used 67-72 SSRs (Win et al. 2012; Singh et al. 2013), Group 3 used 84-97 SSRs (Siangliw et al. 2007; Jantaboon et al. 2011), and Group 4 used 107-205 SSRs (Rajpurohit et al. 2011; Korinsak et al. 2011; Suh et al. 2013). However, the majority of these MAB projects utilized molecular markers during the final stage of selection.

\section{Linkage drag}

In conventional backcrossing, many portions of the donor genomes are inserted into both the carrier and non-carrier recipient chromosomes during early cycles. After continued backcrossing, the donor genome segments are gradually replaced by sequences from the recurrent parent at varying rates. In most backcrossing programs, linkage drag is responsible for long-lasting donor genome segments remaining in the recurrent genome. However, there is no difference in terms of linkage drag in pseudo-backcrossing schemes. In pseudo-backcrossing BILs, there was only a $1 \%$ reduction in linkage drag from $\mathrm{BC}_{1}$ to pseudo- $\mathrm{BC}_{3}$, and most of this reduction was due to the heterozygous segments of the linkage drag. Our results also revealed that the degree of linkage drag is independent of the size of the target genes/QTLs. When comparisons were made between the selection of single genes or single QTLs, the degree of linkage drag was less for QTLs than for single genes. Of the five single gene selections, SSIIa, Sub1, xa5, $X a 21$ and TPS, only selection for Xa21 showed large, persistent linkage drag. Persistent linkage drags when selecting for $\mathrm{BB}$ genes have been reported in several backcross breeding programs, such as during the transfer of $X a 4+x a 5+X a 21$ from indica 'IRBB57' into japonica 'Mangeumbyeo' (Suh et al. 2013), and pyramiding of the $\mathrm{BB}$ resistance genes $\mathrm{Xa} 21$ and $x a 13$ and a semi-dwarfing gene (sd-1) from PR106-P2 into Type 3 Basmati (Rajpurohit et al. 2011). The problem of persistent linkage drag when selecting for $\mathrm{Xa21}$ may due to the fact that $\mathrm{Xa21}$ was derived from IRBB21, which inherited the chromosomal region containing Xa21 from the wild species Oryza longistaminata through several cycles of backcrossing with indica rice (Song et al. 1995). The degree of linkage drag may depend on linkage disequilibrium surrounding the target gene to be transferred. Genes inherited from wild species in cultivated strains may be retained within long, stable LD stretches that are difficult recombine. Therefore, selection based on functional markers alone does not 
guarantee linkage drag-free progeny. More successful single-gene target selection has been reported when markers flanking the gene of interest were also selected for (Rajpurohit et al. 2011). In one of the most comprehensive backcrossing projects, a single gene, $s d 1$, was integrated into the desirable variety 'Koshihikari' using eight cycles of MAB with 51 SSR markers surrounding $s d 1$ to completely eliminate linkage drag (Tomita 2009).

\section{Grain yield performance of pseudo-BC BILs}

In this study, we combined multiple resistance genes from four donors using a new backcrossing method involving pseudo-backcrossing. The results show that all pseudo-BC BILs showed significant improvements in resistance to $\mathrm{BB}, \mathrm{BL}, \mathrm{BPH}$ and Sub compared with the pseudo-recurrent parent 'PinK3', as well as significant improvements in grain yield (21-68\% over the donors, but $7-26 \%$ lower than the recipient). The reduction in grain yield in the pseudo-BC BILs should be interpreted in several ways. First, there was an average of $7.6 \%$ and $22.5 \%$ of linkage drag and DGC, respectively, in the recurrent genome. As these donors were inferior in grain yield with respect to the pseudo-recurrent parent 'PinK3', the high persistent \%DGC could have disrupted the optimal expression of high-yield genes in pseudo-BC BILs. Second, there can be a slow recovery of the \%RGC during pseudo-backcrossing when MAS for the recurrent background is not in place. Under such conditions, reconstruction of the recurrent genome content by recombining different pseudo-backcrossed lines is not favorable, as different donor segments on both carrier and non-carrier chromosomes have more chances to recombine, creating new substitution lines that do not resemble the recurrent parent. Third, the multiple donated genes/ QTLs from donors to the recipient act as a 'genetic load' against the fitness of the recurrent parent. The overexpression of multiple resistance genes could counteract the metabolic energy needs necessary for high yield. Therefore, pseudo-backcrossing may be the fastest method for gene/QTL pyramiding, although it may not be the ideal breeding platform for creating elite recurrent varieties. However, marker-assisted, genomewide scanning can be implemented during early stages to facilitate the reconstruction of favorable genomic backgrounds at the end of the pseudo-backcrossing scheme. Ultimately, the trade-offs must be considered by the breeders. Ideally, new high-throughput, lowcost, genome-wide scanning technologies should be utilized in combination with skillful breeder selection. For the whole project, more than 50,000 plants were individually genotyped for at least one molecular marker. If budget is allow, extensive background selection must be emphasized.

\section{Conclusion}

We improved high-yield, aromatic rice varieties by introducing desirable multiple traits by pyramiding five target genes (Sub1A-C, SSIIa, xa5, Xa21 and TPS) and three QTLs (qBph3, qBL1 and qBL11) from four resistance donors. We redesigned the gene-pyramiding platform to minimize the total project time span by integrating MAS into pseudo-backcross breeding. Consequently, only seven breeding cycles in four years were required to develop new varieties exhibiting multiple resistance traits. Using pseudo-backcrossing, approximately $77.48 \%$ of the recurrent genome background was recovered. With additional background genome selection, the recurrent genome background can further improve the \%RGC and optimize the expression of introgressed QTLs.

\section{Methods}

\section{Plant materials used}

PinK3 is a high-yield, irrigated aromatic rice cultivar developed by Rice Science Center, Kasetsart University, Thailand (unpublished). However, this variety is susceptible to flash flooding (Sub), bacterial leaf blight (BB), leaf-neck blast (BL) and the brown planthopper (BPH). The four donors used to transfer five genes and three QTLs to the pseudo-recurrent parent 'PinK3' (Table 1) were developed by the Rice Gene Discovery and Rice Science Center, Kasetsart University, Thailand. The four donors used to improve the abiotic and biotic stress tolerances of 'PinK3' are listed in Table 1.

\section{Pseudo-backcross design}

The pseudo-backcross platform is divided into three steps. In the initial step, one round of backcrossing is conducted to donate the favorable QTL allele to the recipient background using marker-assisted backcrossing (MAB). Each QTL-BC $\mathrm{C}_{1} \mathrm{~F}_{1}$ contains approximately $75 \%$ of its recurrent genome content (RGC). In the second step, the $\mathrm{BC}_{1} \mathrm{~F}_{1}$-plus QTLs are used as pseudo-recurrent parents, and pseudo- $\mathrm{BC}_{2} \mathrm{~F}_{1}$ plants are formulated by crossing between them. More $\mathrm{BC}_{1} \mathrm{~F}_{1}$ plus new QTLs can be crossed to successively generate pseudo- $\mathrm{BC}_{\mathrm{n}} \mathrm{F}_{1}$ QTLs and, thus, to continue streamline gene pyramiding. At the end of this step, the $\mathrm{BC}_{\mathrm{n}} \mathrm{F}_{1}$, which contains the new QTLs at full heterozygosity at all target marker loci, are self-pollinated to fix the target loci (Additional file 5). In rice, this new platform allows breeders to stack more QTLs in the shortest possible time (shorter than that required by any other method).

\section{Donors for gene pyramiding in rice}

Four donors providing submergence tolerance, bacterial leaf blight resistance, blast resistance, $\mathrm{BPH}$ resistance and desired gelatinization temperature were introduced into PinK3 (aroaro and $W x^{A} W x^{A}$ ) as the female pseudo- 
recurrent parent. The donor CholSub1 carries two target traits: submergence tolerance and desired gelatinization temperature (Sub1A-C and SSIIa); the donor Xa497 carries two functional genes for bacterial leaf blight resistance ( $x a 5$ and Xa21); the donor RBPiQ carries two QTLs for blast resistance (qBL1 and qBL11); and the donor Bph162 carries two target traits for BPH resistance (qBph3 and TPS) (Table 1). These four donors were used for gene pyramiding.

\section{Genomic DNA isolation}

Rice seedlings from each segregating population were grown in a 288-well plastic tray (representing three 96well plates). Young leaves from 14-day-old individual plants were cut into small pieces and placed $(\sim 0.2 \mathrm{~g}$ weight per sample) in a 2-ml 96-well plastic block. Leaf tissues were ground in liquid $\mathrm{N}_{2}$ using a Tissue Striker II (KisanBio, Seoul, South Korea). After grinding, $300 \mu \mathrm{l}$ Agencourt ${ }^{\circ}$ Chloropure lysis buffer was added to the samples. Homogenized tissues were incubated in a 2-ml 96-well plastic block at $65^{\circ} \mathrm{C}$ for 1 hour. The sample blocks were then centrifuged at 4,000 rpm for $10 \mathrm{mi}$ nutes. Lysates (containing at least $200 \mu \mathrm{l}$ ) were transferred to a new 2-ml 96-well plastic block using an Automated Biomeck NX AP96 instrument (Beckman Coulter, California, USA). The extraction was conducted using the standard protocol of Agencourt Chloropure for nucleic acid isolation from plants (Beckman Coulter, California, USA).

\section{Foreground MAS}

Foreground selection was performed using two marker systems. For SNP and functional markers, multiplex genotyping was conducted using the SNPstream system (Beckman Coulter, California, USA). The remainder of the foreground markers were SSR markers flanking specific QTLs. The SNP-based genotyping array was described.

\section{High-throughput multiplex SNP genotyping}

High-throughput genotyping was performed by multiplex PCR, as described by Bell et al. (2002) with certain modifications. In brief, the forward/reverse (18-20 nt in length) and SNP-specific (40-45 nt in length) primers were designed for each foreground locus (Primers can be manually designed) to generate a product of $90-180 \mathrm{nt}$ in size. The program selects the best Single Base Extension (SBE)-primer based on sequence melting temperature $\left(\mathrm{T}_{\mathrm{m}} ;{ }^{\circ} \mathrm{C}\right)$ and secondary structure. At the $5^{\prime}$ end of the SBE-primer sequences are 20-nt tags that are complementary to the sequences of specific positional tags in the SNPware (384-well) microarray format (Beckman Coulter, California, USA) (Table 6).

\section{Multiplex PCR}

A $10-\mu \mathrm{l}$ PCR reaction containing $5 \mu \mathrm{l}$ genomic DNA $(10 \mathrm{ng} / \mu \mathrm{l})$ and $5 \mu \mathrm{l} \mathrm{KAPA} \mathrm{TaqHotStart} \mathrm{PCR} \mathrm{buffer} \mathrm{(1} \mathrm{U}$ KAPA TaqHotStart (KapaBiosystems, MA, USA) (final concentration of $1 \times$ KAPA TaqHotStart Buffer: $75 \mu \mathrm{M}$ dNTPs, $5 \mathrm{mM} \mathrm{MgCl}_{2}$ and $50 \mathrm{nM}$ 38-primer pool) was performed in a 384-well PCR plate (Sorenson BioScience, UT, USA). The following thermocycler touch-up PCR cycle was used: $95^{\circ} \mathrm{C}$ for $3 \mathrm{~min}$, followed by 6 cycles of $95^{\circ} \mathrm{C}$ for 30 seconds, $50^{\circ} \mathrm{C}$ up to $55^{\circ} \mathrm{C}$ (0.3 increment/ cycle) for 30 seconds, and $72^{\circ} \mathrm{C}$ for 30 seconds; this was followed by 34 cycles of $95^{\circ} \mathrm{C}$ for 30 seconds, $55^{\circ} \mathrm{C}$ for 30 seconds, $72^{\circ} \mathrm{C}$ for 30 seconds and a final extension at $72^{\circ} \mathrm{C}$ for $7 \mathrm{~min}$. Subsequently, the temperature was held at $4^{\circ} \mathrm{C}$.

Multiplex PCR assays were prepared separately based on the SNP panel type (A/G, A/C, A/T, G/C, G/T and $\mathrm{C} / \mathrm{T})$. Following PCR amplification, PCR products were cleaned, and the SBE reactions were performed. Next, multiplex SBE products from different panel types were pooled prior to the hybridization step.

PCR clean up, SBE reactions, hybridization and washing, SNPstream imaging and data analysis were performed as described by Bell et al. (2002).

\section{Evaluation of abiotic and biotic stress traits \\ Submergence screening}

The parents and pseudo- $\mathrm{BC}_{3} \mathrm{~F}_{3} \mathrm{BILs}(\mathrm{PinK}+4)$ were screened for submergence resistance traits. The experiment was conducted under complete submergence in an outdoor lagoon located at the Rice Science Center, Kasetsart University, Kamphaeng Sean Campus, Thailand, during the dry season of 2013. The experiment was arranged using a randomized complete block design with three replications. Sixteen three-week-old $\mathrm{BC}_{3} \mathrm{~F}_{3} \mathrm{BIL}$ seedlings and controls including PinK3, CholSub, Xa497, RBPiQ and Bph162 were transplanted in three replicate plots (plot size: $0.75 \times 0.75 \mathrm{~m}^{2}$ ) at a spacing of $25 \mathrm{~cm} \times$ $25 \mathrm{~cm}$. Two weeks after transplanting, the number of seedlings was counted in each plot; then, the lagoon was filled with water to a depth of $2 \mathrm{~m}$. To impose severe submergence stress, the seedlings were completely submerged for 15 days; the water level was maintained at 1-1.2 m above the leaf tip throughout the experimental period. After this period, the lagoon was drained, and the seedlings were re-exposed to air for 10 days (Jantaboon et al. 2011). The number of surviving plants was recorded. The percentage of survival (PS) was calculated using the following equation:

$$
\text { PS }=\frac{\text { Number of surviving plants }}{\text { Total number of plants }} \times 100
$$


Table 6 Primer sequences used in the SNP genotyping format for foreground selection

\begin{tabular}{|c|c|c|c|c|c|c|c|c|c|}
\hline No. & SNP name & Chr. & Trait & $\begin{array}{l}\text { Tag } \\
\text { number }\end{array}$ & $\begin{array}{l}\text { SNP } \\
\text { type }\end{array}$ & $\begin{array}{l}\text { Amplicon } \\
\text { size (bp) }\end{array}$ & Forward primer $\left(5^{\prime}-3^{\prime}\right)$ & Reverse primer $\left(5^{\prime}-3^{\prime}\right)$ & SNP-specific primer $\left(5^{\prime}-3^{\prime}\right)$ \\
\hline 1 & Sub1C & 9 & Sub & 9 & $A / G$ & 111 & ACGAGCCGACGACGACGA & ATCTCCGACGCCCACCTC & CCGCCAGTAAGACCTAGACGCGGCGGCGGCGGCGGCGGAGGGAGA \\
\hline 2 & $x_{a} 5^{*}$ & 5 & $\mathrm{BB}$ & 2 & $C / G$ & 303 & GGCCACCTTCGAGCTCTACC & CAACATTGCAACTCCGTGATAAG & CTCAGACTACGAATCCACGTGTAAAGTAGATACCTTATCAAACTG \\
\hline 3 & Xa21 & 11 & BLQ11 & 40 & $\mathrm{~T} / \mathrm{C}$ & 141 & AAAGCTAGGCTGCTAGTGCTG & AAAATAGTATATATGTACCACTGCTTCTT & AAGTACCACGTCAACGTCACTATGCTTCAAGGTCAGGGTGGTCGA \\
\hline 4 & SSIlla & 6 & GT & 25 & $\mathrm{G} / \mathrm{T}$ & 89 & CCACTGCCTCGAGACGTA & CGTGGTCCCAGCTGAGGT & CCATAACAACTTACCAGCCAGCAAGTACAAGGAGAGCTGGAGGGG \\
\hline 5 & Waxy & 6 & $A C$ & 31 & $\mathrm{G} / \mathrm{T}$ & 141 & TTCACTTCTCTGCTTGTGTTGT & TACTTGTAAGGAAAAACGAGCAA & CAGAACATCCTCAGAAGCAAGTTCATCAGGAAGAACATCTGCAAG \\
\hline 6 & aromarker* & 8 & $\mathrm{FR}$ & 41 & $A / G$ & 400 & AATCATGTATACCCCATCAA & TाTCCACCAAGTTCCAGTGA & TACCTATGACCAGCAAGCACAACCTTAACCATAGGAGCAGCTGAA \\
\hline 7 & $\mathrm{Hd} 1$ & 6 & Photo & 13 & $C / G$ & 152 & TCCAAAGATTCCGACAACA & TTGTCGTAGTACGAATTGTACCC & CAACAATACGAGCCAGCAAGACAACAACAACGACAACGACAATAA \\
\hline 8 & $\begin{array}{l}\text { TPS_Chr4_ } \\
\text { ATHB1* }\end{array}$ & 4 & Bph3 & 27 & $T / G$ & 264 & AAGCGCTTATATTCAAGCAGAA & TCCATTCTTCCGATCTCTGG & GCAAGCCATCAGCTAATACATTCATGAAACAGTTCTAGCAATAAT \\
\hline 9 & $\begin{array}{l}\text { Bph_Chr6_ } \\
1210^{*}\end{array}$ & 6 & Bph3 & 17 & $\mathrm{~T} / \mathrm{C}$ & 287 & GAAAGCCTITGAAACAAAGTATTGA & CTTGAATTTGAGTTGATTTTAGGG & GCAGACAACGAACAACTACCAAACGGCATATTTGCAAACAGAAAA \\
\hline 10 & $\begin{array}{l}\text { Bph_Chr6_ } \\
3380^{*}\end{array}$ & 6 & Bph3 & 22 & $\mathrm{~T} / \mathrm{C}$ & 300 & AGAGGAAATGATTCAAGGAG & AGCTAGCAGGCGTAGCTTAT & GCAACATAAGACCGCTCAACTAGTTAATTTCACGCCATGACAGAT \\
\hline 11 & $\begin{array}{l}\text { Bph_Chr6_ } \\
1380^{*}\end{array}$ & 6 & Bph3 & 19 & $A / G$ & 296 & TTITTTITCTTCTTGAGAGTGGTC & CAAGGTAATGACATCAAGAACCAAT & CCACTCAACTCCACGAATACCACATGTTTATTTTAATTCACAG \\
\hline 12 & TBGI055716 & 1 & BLQ1 & 24 & T/A & 169 & ACGATGCGGCACTCGTCG & TGTTCTTGAACGCGGCGA & CAACAAGACATAACAACGCAGTGGAGTGGTGGATGAAGCGGAAGA \\
\hline 13 & TBGI055578 & 1 & BLQ1 & 42 & $A / G$ & 93 & ATTTGCTGCTCATGGTGG & TGGGGAAGCCGAGGAGAT & СTCACTATCTGACAAGCCACGTGGAGCCTCCTCACCAGGAAGTGC \\
\hline 14 & TBGI055841 & 1 & BLQ1 & 46 & $\mathrm{~T} / \mathrm{C}$ & 115 & ATTGGCATCGTTTGGTCTG & ATTCCGTGCATATATACGAACTTC & ACAGATCACTCACCGACTAAATACCTGCGTCGAGTAGAGACGATG \\
\hline 15 & TBG|454069 & 11 & BLQ11 & 14 & $A / G$ & 142 & TGAATTGTCGTCCTCTAACAAC & TATGGAATATCTGCATCATGAAC & AACATACAGACGCACTCCTCTCTITGCTATGCCAAAGTCTGCTAC \\
\hline 16 & TBG|453598 & 11 & BLQ11 & 23 & $\mathrm{C} / \mathrm{T}$ & 90 & TTTGCTGTGACGGGAAGA & AAAAAGGAACTAGCCAGTITTG & AGTAGCCTAACAGCACTCGAAAGATCGAGTGCTCTATTGCAACCG \\
\hline 17 & TBG|453126 & 11 & BLQ11 & 32 & $\mathrm{C} / \mathrm{T}$ & 92 & ACCGACGCTGCTGCAGAA & AGCGGTTATGGATGGCTAA & CAAGCAACGACCTACTACAAGCATGGCGTTTGAGCGCGTCCTGGG \\
\hline 18 & TBG|454717 & 11 & BLQ11 & 36 & T/A & 132 & ATCCTACCGTCCGCTCTG & AATTCGGTCTTCGTAAACACG & CACCGCTATCAACAGACTTGGTGCGGTAGTTTCTGGGAAGCTACG \\
\hline 19 & TBGI454800 & 11 & BLQ11 & 38 & $\mathrm{G} / \mathrm{C}$ & 113 & TACTACAACAACAGGAACGCC & TTGATGATGAAGTGGATGAGC & ACGTAAGACCACTCAAGACCAGAAGACGCTGAACAGGATGGCGAT \\
\hline
\end{tabular}

${ }^{*}$ These primer designs were optimized manually. 


\section{Brown planthopper (BPH) screening}

A set of pseudo- $\mathrm{BC}_{3} \mathrm{~F}_{3} \mathrm{BILs}(\mathrm{PinK}+4)$ and their parents were screened for resistance against $\mathrm{BPH}$ using standard seedbox screening (SSBS); the BPH population used was collected from Ubon Ratchathani provinces (Jairin et al. 2007). The SSBS was conducted at the seedling stage (10 days old) under greenhouse conditions following the method described by Heinrichs et al. (1985). Damage scores were recorded when the susceptible control, 'TN1', died (9 days after infestation; 9DAI), using the standard evaluation system (IRRI 1996).

\section{Bacterial leaf blight screening}

The Xoo isolate TXO156 was selected for this experiment. The isolate was grown following the method described by Win et al. (2012). The parents and pseudo$\mathrm{BC}_{3} \mathrm{~F}_{3} \mathrm{BILs}(\mathrm{PinK}+4)$ were grown in a greenhouse for 30 days before inoculation. The inoculation procedures used were adapted from those described by Korinsak et al. (2009a, b). Three to four fully expanded leaves of each plant were inoculated. Lesion length (LL) was measured at 12-14 days after inoculation. The resistance reaction was classified as resistant (R), moderately resistant (MR), moderately susceptible (MS) and susceptible (S) when the values of LL were $0-3 \mathrm{~cm}, 3.1-6 \mathrm{~cm}, 6.1-9 \mathrm{~cm}$ and more than $9 \mathrm{~cm}$, respectively (Yang et al. 2003; Lin et al. 1996).

\section{Leaf blast screening}

Thailand Magnaporthe oryzae mixed isolates\#2, including THL710 (Mae Hong Son), THL282 (Phrae), THL906 (Yala), THL122 (Chiang Rai), THL757 (Mae Hong Son) and THL603 (Surin) (Rice Gene Discovery, Thailand, unpublished), which can damage the PinK3 form in the mixed isolate pre-screening, was used in leaf blast screening experiments. The inoculum was prepared and the plants were inoculated following the method described by Marchetti et al. (1987) with some modifications. Pseudo- $\mathrm{BC}_{3} \mathrm{~F}_{3} \mathrm{BILs}(\mathrm{PinK}+4)$ and their parents were grown in polyvinyl trays containing paddy field soil (four seedlings per line) following a three-replication completely randomized design (CRD). The seedlings were maintained in a greenhouse for 17 days before inoculation, after which they were inoculated with mixed isolates\#2. Disease scoring was recorded at seven days after inoculation on a 0 to 6 scale following the procedure described by Roumen et al. (1997) and IRRI (2002). The average score of each line was computed from the disease score measured for 12 individual plants.

\section{Recording of important agronomic traits}

Traits measured included days to 100\% flowering (DF100), days to maturity (DM), number of tillers per plant (NTP), plant height (PH), number of grains per panicle (NGP), percent spikelet fertility (PSF), 1,000 grain weight (TGW) and grain yield (GY); these traits were measured for rice plants grown during field trials at Kasetsart University, Kamphaeng Sean, Nakhon Pathom, Thailand.

Twenty-one-day-old seedlings were transplanted in three replicates in $1 \times 2 \mathrm{~m}^{2}$ plots using $25 \times 25 \mathrm{~cm}^{2}$ plant spacing. Agronomic traits were recorded for five randomly selected plants grown in each plot. The DF was recorded when $100 \%$ of the individual plants in each plot flowered. NTP, PH, NGP and DM were measured at maturity, and the results were averaged from five randomly selected plants in each plot. PH was measured from the soil surface to the neck of the panicle. The NGP was counted manually for five panicles. To measure the GY in each plot, only the inner rows (containing 21 plants) were used. Two border rows on each side of the plot and the border plants of each row were discarded. The GY recorded for each plot was adjusted to $14 \%$ moisture content and then extrapolated to units of $\mathrm{kg}$ per ha. TGW measurements were replicated three times. Statistical analysis was performed using the STATGRAPHICS plus 3.0 software package (Manugistics 1997).

\section{Evaluation of grain quality}

Grain quality was evaluated using grain harvested from the trials field. Rice grains of the pseudo- $\mathrm{BC}_{3} \mathrm{~F}_{3} \mathrm{BILs}(\mathrm{PinK}+4)$ and their parents were harvested at physiological maturity and sun-dried in a greenhouse. The dried grains were stored at room temperature for one month prior to the grain quality traits evaluation. Three hundred grams of grains was sampled from each replicate. The grains were mechanically dehulled and polished using a mini-polisher. Four physical grain qualities, including percentages of brown rice (BR), head rice (HR), grain length $(\mathrm{GL} / \mathrm{W})$ and \%cooking elongation increased (CE), were evaluated for the polished rice. Ten grains of paddy rice were measured using a Vernier caliper, and the GL/W ratio was calculated. The polished rice grain length (PRL) was measured using the same method. The cooking elongation of the polished rice was determined by boiling 20 grains in $5 \mathrm{ml}$ of $\mathrm{dH}_{2} \mathrm{O}$ for ten minutes. Cooked grain lengths were measured after air-drying the grains for 1 hour. Two chemical grain qualities, amylose content (AC) and gel temperature (GT), were evaluated following the procedures described by Lanceras et al. (2000). GT is an indicator of the time required for cooking. The GT was indirectly estimated based on the alkali spreading value (ASV); higher values of ASV represent increased spreading in alkali and therefore represent lower values of GT; conversely, smaller values of ASV indicate higher values of GT.

\section{Genomic scanning of foreground and background}

Using simple sequence repeat (SSR) markers spanned across the genome, the effects of foreground selection on 
linkage drag and genome background content were estimated using the graphical genotyping software GGT 2.0 (Berloo 2007) based on a specific $\mathrm{F}_{2}$ population type calculation. The effects of marker-assisted selection were studied on $\mathrm{BC}_{1} \mathrm{~F}_{2}$ and pseudo-backcross progeny after recombining all target genes/QTLs (PinK +4$)$. Five selected $\mathrm{BC}_{1} \mathrm{~F}_{2}$ (Additional file 2) and nine pseudo- $\mathrm{BC}_{3} \mathrm{~F}_{3} \mathrm{BILs}$ $($ PinK + 4) (Additional file 3) representing nine recombined families were analyzed for genetic background recovery; 61 SSR markers showing clear polymorphism between parents were used (Additional file 1). Twenty-six markers distributed over six non-carrier chromosomes (chromosomes 2, 3, 7, 8, 10 and 12), as well as 35 SSR markers distributed over six carrier chromosomes (chromosomes 1, 4, 5, 6, 9 and 11) were used for background scanning. Furthermore, QTL-specific markers located within each QTL were developed to estimate the risk of target loss. Definitions of parameters describing \% recurrent genome content (\%RGC) and \% donor genome content (\%DGC) were calculated according to $\mathrm{Xi}$ et al. (2006), (Suh et al. (2009) and Suh et al. (2013) with some modification.

Donor segment link: homozygous allele similar to each donor on the same arm of the carrier chromosome.

Heterozygous segment link: heterozygous allele on the same arm of the carrier chromosome.

Donor segment unlink: homozygous allele similar to each donor on the other arm of the carrier chromosome.

Heterozygous segment unlink: heterozygous allele on the other arm of the carrier chromosome.

Donor segments on non-carrier chromosome: homozygous allele similar to each donor on non-carrier chromosomes.

Heterozygous segments on non-carrier chromosomes: heterozygous allele on non-carrier chromosomes.

Recurrent background: homozygous allele similar to the pseudo-recurrent 'PinK3' allele.

\section{Additional files}

Below is the link to the electronic supplementary material.

Additional file 1: Polymorphic SSR markers used for background survey and QTL/functional markers for foreground selection using physical distance (Pseudomoleculerelease7) on carrier and non-carrier chromosomes.

Additional file 2: The genomic composition (average per line) of five selected $B C_{1} F_{2}$ lines resulting from four donors: CholSub1, Xa497, RBPiQ and Bph162.

Additional file 3: The percentage of genome compositions (average per line) of nine selected pseudo- $\mathrm{BC}_{3} \mathrm{~F}_{3} \mathrm{BILs}$.

Additional file 4: Average lesion length in centimeters of pseudo$\mathrm{BC}_{3} \mathrm{~F}_{3} \mathrm{BILs}(\mathrm{PinK}+4)$ as well as the donor and recurrent parents when challenged with four Thai Xanthomonas oryzae pv. oryzae isolates.

Additional file 5: Pseudo-backcrossing scheme for multiple gene pyramiding based on one single backcrossing to maintain the percentage of recurrent genome content at $75 \%$ in the successive pseudo-backcrossing phase. This novel platform facilitates the introduction of additional genes/QTLs to be pyramided into the current genotyping design. Once the desirable genotype is constructed, selfing, MAS and phenotypic selection increase the likelihood of optimizing the desirable pyramided lines.

\section{Abbreviations}

\%RGC: Recurrent genome content; \%DGC: Donor genome content; $\mathrm{BC}_{n} \mathrm{~F}_{n}$ : Pseudo-backcrossing; Sub: Submergence; BB: Bacterial leaf blight; BL: Blast; BPH: Brown planthopper; MAB: Marker-assisted backcrossing.

\section{Competing interests}

The authors declare that they have no competing interests.

\section{Authors' contributions}

SR and SP performed the cross-hybridization and MAB screening experiments. EC developed the SNP marker set used for MAB. WK and WS performed the $\mathrm{BPH}$ infestation experiments and identified candidate genes for $\mathrm{BPH}$ resistance. EP performed the submergence screening. SK and SK performed the BB and BL screenings. The entire study was designed and coordinated by AV. SR drafted the manuscript, and AV corrected the manuscript's draft. All authors read and approved the final version of the manuscript.

\section{Acknowledgments}

This work was supported by the Agriculture Research Development Agency (ARDA) (Grant No. P12/2552). SR gratefully acknowledges financial support from the Royal Golden Jubilee (RGJ)-PhD program, Grant No. PHD/0009/ 2546, from the Thailand Research Fund (TRF).

\section{Author details}

${ }^{1}$ Rice Science Center, Kasetsart University, Kamphaeng Saen, Nakhon Pathom 73140, Thailand. ${ }^{2}$ Interdisciplinary Graduate Program in Genetic Engineering, Kasetsart University, Chatuchak, Bangkok 10900, Thailand. ${ }^{3}$ Rice Gene Discovery, National Center for Genetic Engineering and Biotechnology (BIOTEC) National Science and Technology Development Agency (NSTDA), Kasetsart University, Kamphaengsaen, Nakhon Pathom 73140, Thailand.

${ }^{4}$ Agronomy Department, Faculty of Agriculture at Kamphaeng Saen, Kasetsart University, Kamphaeng Saen, Nakhon Pathom 73140, Thailand.

Received: 7 July 2014 Accepted: 10 December 2014

Published online: 05 February 2015

\section{References}

Ashikari M, Matsuoka M. Identification, isolation and pyramiding of quantitative trait loci for rice breeding. Trends Plant Sci. 2006;11(7):344-50.

Bao JS, Sun M, Zhu LH, Corke H. Analysis of quantitative trait locus for some starch properties in rice (Oryza sativa L.), thermal properties, gel texture, swelling volume. J Cereal Sci. 2004;39:379-85.

Bao JS, Corke H, Sun M. Nucleotide diversity in starch synthase lla and validation of single nucleotide polymorphisms in relation to starch gelatinization temperature and other physicochemical properties in rice (Oryza sativa L.). Theo App Genet. 2006a;113:1171-83.

Bao JS, Shen SQ, Sun M, Corke H. Analysis of genotypic diversity in the starch physicochemical properties of non-waxy rice: apparent amylose content, pasting viscosity and gel texture. Starch-Starke. 2006b;58:259-67.

Bell PA, Chaturvedi S, Gelfand CA, Huang CY, Kochersperger M, Kopla R, et al. SNPstream UHT: ultra-high throughput SNP genotyping for pharmacogenomics and drug discovery. Biotechniques. 2002;32:S70-7.

Berloo RV. GGT 2.0 user manual. Laboratory of plant breeding. Netherland: Wageningen University; 2007.

Bouman BAM, Lampayan RM, Tuong TP (2007) Water management in irrigated rice: coping with water scarcity. International Rice Research Institute (IRRI), Los Baños, Philippines. http://www.knowledgebank.irri.org/ewatermgt/ courses/course1/resources/books/water_management_1.pdf.

Bouquet A. Introduction dansl'espece Vitis vinifera $\mathrm{L}$. d'un caractere de resistance al'oidium (UncinulanecatorSchw. Burr) issul'espece Muscadinia rotundifolia (Michx) Small. Vignevini. 1986;12(suppl):141-6.

Heinrichs EA (1979) Chemical control of the brown planthopper. In: Brown planthopper: Threat to rice production in Asia, IRRI Publications, Los Baños, Philippines, pp. 145-167. 
Heinrichs EA, Medrano FG, Rapusas HR. Genetic Evaluation for Insect Resistance in Rice. Los Baños, Philippines: IRRI; 1985.

IRRI. Standard Evaluation System for Rice. Manila, Philippines: IRRI; 1996.

IRRI. Standard Evaluation System for Rice (SES). Los Banos, Philippine: International Rice Research Institute; 2002.

Jairin J, Phengrat K, Teangdeerith S, Vanavichit A, Toojinda T. Mapping of a broad-spectrum brown planthopper resistance gene, Bph3, on rice chromosome 6. Mol Breed. 2007;19:35-44.

Jairin J, Teangdeerith S, Leelagud P, Kothcharerk J, Sansen K, Yi M, et al. Development of rice introgression lines with brown planthopper resistance and KDML105 grain quality characteristics through marker-assisted selection. Field Crop Res. 2009;110(3):263-71.

Jantaboon J, Siangliw M, Im-mark S, Jamboonsri W, Vanavichit A, Toojinda T. Ideotype breeding for submergence tolerance and cooking quality by marker-assisted selection in rice. Field Crop Res. 2011;123(3):206-13.

Jena KK, Jeung JU, Lee JH, Choi HC, Brar DS. High-resolution mapping of a new brown planthopper (BPH) resistance gene, Bph18(t), and marker-assisted selection for BPH resistance in rice (Oryza sativa L.). Theor Appl Genet. 2006;112:288-97.

Joshi RK, Nayak S. Gene pyramiding-a broad spectrum technique for developing durable stress resistance in crops. Biotechnology and Molecular Biology. 2010:5(3):51-60

Kamolsukyunyong W, Sukhaket W, Ruanjaichon V, Toojinda T, Vanavichit A. Single-feature polymorphism mapping of isogenic rice lines identifies the influence of terpene synthase on brown planthopper feeding preferences. Rice. 2013;6:18

Kate-ngam S, Kimchaiyong W, Wanchana S, Toojinda T. Association analysis and functional marker development of soluble starch synthase lla (SSIla) and gelatinization properties in Thai rice. In: Proceeding of the 5th International Crop Science Congress \& Exhibition: Recognizing Past Achievements, Meeting Future Needs April 13-18, 2008. Jeju, Korea: International Convention Center; 2008.

Kawaguchi M, Murata K, Ishii T, Takumi S, Mori N, Nakamura C. Assignment of a brownplanthopper (NilaparvatalugensStål) resistance gene bph4 to the rice chromosome 6. Breed Sci. 2001;51:13-8.

Korinsak S. Marker-assisted pyramiding bacterial blight resistance genes ( $x a 5, \mathrm{Xa21}$, $x a 33(t), X a 34(t)$ and $q B B 11)$ in rice. Dissertation: Kasetsart University; 2009.

Korinsak S, Sirithanya P, Toojinda T. Identification of SSR markers linked to a bacterial blight resistance gene in rice cultivar 'Pin Kaset'. KKU Res J (GS). 2009a;9:16-21.

Korinsak S, Sriprakhon S, Sirithanya P, Jairin J, Korinsak S, Vanavichit A, et al. Identification of microsatellite markers (SSR) linked to a new bacterial blight resistance gene xa33 (t) in rice cultivar 'Ba7'. Maejo Int J Sci Technol. 2009b:3:235-47.

Korinsak S, Sirithunya P, Meakwatanakarn P, Sarkarung S, Vanavichit A, Toojinda T. Changing allele frequencies associated with specific resistance genes to leaf blast in backcross introgression lines of Khao Dawk Mali 105 developed from a conventional selection program. Field Crops Res. 2011;122(1):32-9.

Kullan ARK, Van Dyk MM, Jones N, Kanzler A, Bayley A, Myburg AA, et al. Highdensity genetic linkage maps with over 2,400 sequence-anchored DArT markers for genetic dissection in an $F_{2}$ pseudo-backcross of Eucalyptus grandis $\times$ E. urophylla. Tree Genetics \& Genomes. 2012;8:163-75.

Lanceras J, Huang ZL, Naivikul O, Vanavichit A, Ruanjaichon V, Tragoonrung S. Mapping of genes for cooking and eating qualities in Thai jasmine rice (KDML105). DNA Res. 2000;7:93-101.

Lin XH, Zhang DP, Xie YF, Gao HP, Zhang Q. Identifying and mapping a new gene for bacterial blight resistance in rice based on RFLP markers. Phytopathology. 1996;86:1156-9.

Lu Y, Xiao P, Shao Y, Zhang G, Thanyasiriwat T, Bao J. Development of new markers to genotype the functional SNPs of SSIlla, a gene responsible for gelatinization temperature of rice starch. J Cereal Sci. 2010;52:438-43.

Luo Y, Yin Z. Marker-assisted breeding of Thai fragrance rice for semi-dwarf phenotype, submergence tolerance and disease resistance to rice blast and bacterial blight. Mol Breeding. 2013;32:709-21.

Maclean JL, Dawe DC, Hardy B, Hettel GP. Rice Almanac. 3rd ed. Philippines: IRRI, WARDA, CIAT and FAO; 2002.

Manugistics. Statgraphics Plus for Windows 3.0. Manugistics Group, Inc., Rockville: Maryland, USA; 1997.

Marchetti MA, Lai X, Bollich CN. Inheritance of resistance to Pyriculariaoryzaein rice cultivar grown in the United States. Phytopathology. 1987;77:799-804.

Masouleh AK, Waters DLE, Reinke RF, Ward R, Henry RJ. SNP in starch biosynthesis genes associated with nutritional and functional properties of rice. Sci Rep. 2012;2:557.
Molnár S, Galbács Z, Halász G, Hoffmann S, Kiss E, Kozma P, et al. Marker assisted selection (MAS) for powdery mildew resistance in a grapevine hybrid family. Vitis. 2007:46(4):212-3.

Montoya C, Cochard B, Flori A, Cros D, Lopes R, Cuellar T, et al. Genetic architecture of palm oil fatty acid composition in cultivated oil palm (Elaeis guineensis Jacq.) Compared to its wild relative E. oleifera (H.B.K) Cortés. PLoS ONE. 2014;9(5):e95412. doi:10.1371/journal.pone.0095412.

Noenplab A, Vanavichit A, Toojinda T, Sirithunya P, Tragoonrung S, Sriprakhon S, et al. QTL mapping for leaf and neck blast resistance in KhaoDawk Mali 105 and Jao Horn Nin recombinant inbred lines. Sci Asia. 2006;32(2):133-42.

Novaes E, Osorio L, Drost DR, Miles BL, Boaventura-Novaes CR, Benedict C, et al, Quantitative genetic analysis of biomass and wood chemistry of Populus under different nitrogen levels. New Phytol. 2009;182:878-90.

Ou SH. Kew Surrey: Common wealth Mycological Institute. 2nd ed. 1985. p. 380.

Rajpurohit D, Kumar R, Kumar M, Paul P, Awasthi AA, Basha PO, et al. Pyramiding of two bacterial blight resistance and a semi dwarfing gene in type 3 Basmati using marker-assisted selection. Euphytica. 2011;178:111-26.

Randhawa HS, Mutti JS, Kidwell K, Morris CF, Chen X, Gill KS. Rapid and targeted introgression of genes into popular wheat cultivars using marker-assisted background selection. PLOS ONE. 2009;4(6):e5752.

Roumen E, Levy M, Nottegham JL. Characterization of the European pathogen population of Magnaporthe grisea by DNA fingerprinting and pathotype analysis. European J PI Path. 1997;103:363-71.

Servin B, Martin OC, Mézard M. Toward a theory of marker-assisted gene pyramiding. Genetics. 2004;168:513-23.

Siangliw M, Toojinda T, Tragoonrung S, Vanavichit A. Thai jasmine rice carrying QTLch9 is submergence tolerance. Ann Bot. 2003;91:255-61.

Siangliw JL, Jongdee B, Pantuwan G, Toojinda T. Developing KDML105 backcross introgression lines using marker-assisted selection for QTLs associated with drought tolerance in rice. ScienceAsia. 2007;33:207-14.

Singh A, Singh VK, Singh SP, Pandian RTP, Ellur RK, Singh D, Bhowmick PK, Krishnan SG, Nagarajan M, Vinod KK, Singh UD, Prabhu KV, Sharma TR, Mohapatra T, Singh AK (2012) Molecular breeding for the development of multiple disease resistance in Basmati rice. AoB PLANTS: pls029; doi:10.1093/ aobpla/pls029, available online at www.aobplants.oxfordjournals.org.

Singh VK, Singh A, Singh SP, Ellur RK, Singh D, Krishnan SG, et al. Marker-assisted simultaneous but stepwise backcross breeding for pyramiding blast resistance genes Piz5 and Pi54 into an elite Basmati rice restorer line 'PRR78'. Plant Breed. 2013;132:486-95.

Sirithunya P, Tragoonrung S, Vanavichit A, Pa-in N, Vongsaprom C, Toojinda T. Quantitative trait loci associated with leaf and neck blast resistance in recombinant inbred line population of rice (Oryza sativa). DNA Res. 2002;9:79-88.

Song WY, Wang GL, Chen LL, Kim HS, Pi LY, Holsten T, et al. A receptor kinaselike protein encoded by the rice disease resistance gene, Xa21. Science. 1995;270:1804-6.

Sreewongchai T, Toojinda T, Thanintorn N, Kosawang C, Vanavichit A, Tharreau D, et al. Development of elite indica rice lines with wide spectrum of resistance to Thai blast isolates by pyramiding multiple resistance QTLS. Plant Breed. 2010;129(2):176-80.

Suh JP, Roh JH, Cho YC, Han SS, Kim YG, Jena KK. The Pi40 gene for durable resistance to rice blast and molecular analysis of Pi40-advanced backcross breeding lines. Phytopathology. 2009;99:243-50.

Suh JP, Jeung JU, Noh TH, Cho YC, Park SH, Park HS, et al. Development of breeding lines with three pyramided resistance genes that confer broadspectrum bacterial blight resistance and their molecular analysis in rice. Rice. 2013;6:5

Sun L, Su C, Wang C, Zai H, Wan J. Mapping of a major resistance gene to brown planthopper in the rice cultivar Rathu Heenati. Breed Sci. 2005;55:391-6.

Sun L, Liu Y, Jiang L, Su C, Wan J. Identification of quantitative trait loci associated with resistance to brown planthopper in the indica rice cultivar Col.5 Thailand. Hereditas. 2006;144:48-52.

Sundaram RM, Vishnupriya MR, Biradar SK, Laha GS, Reddy GA, Rani NS, et al. Marker assisted introgression of bacterial blight resistance in Samba Mahsuri, an elite indica rice variety. Euphytica. 2008;160:411-22.

Tian Z, Qian Q, Liu Q, Yan M, Liu X, Yan C, et al. Allelic diversities in rice starch biosynthesis lead to a diverse array of rice eating and cooking qualities. PNAS. 2009;106(51):21760-5.

Tomita M. Introgression of green revolution sd1 gene into isogenic genome of rice super cultivar Koshihikari to create novel semidwarf cultivar 'Hikarishinseiki' (Koshihikari-sd1). Field Crops Res. 2009;114:173-81. 
Umemoto T, Aoki N. Single-nucleotide polymorphisms in rice starch synthase lla that alter starch gelatinization and starch association of the enzyme. Funct Plant Bio. 2005;32:763-8.

Umemoto T, Yano M, Satoh H, Shomura A, Nakamura Y. Mapping of a gene responsible for the difference in amylopectin structure between japonicatype and indica-type rice varieties. Theor Appl Genet. 2002;104:1-8.

Umemoto T, Aoki N, Lin HX, Nakamura Y, Inouchi N, Sato Y, et al. Natural variation in rice starch synthase lla affects enzyme and starch properties. Funct Plant Bio. 2004;31:671-84

Wang P, Xing YZ, Li ZK, Yu SB. Improving rice yield and quality by QTL pyramiding. Mol Breeding. 2012;29(4):903-13.

Watanabe T, Kitagawa H. Photosynthesis and translocation of assimilates in rice plants following phloem feeding by the planthopper Nilaparvata lugens (Homoptera: Delphacidae). J Econ Entomol. 2000;93:1192-8.

Waters DL, Henry RJ, Reinke RF, Fitzgerald MA. Gelatinization temperature of rice explained by polymorphisms in starch synthase. Plant Biotechnol J. 2006;4(1):115-22.

Win KM, Korinsak S, Jantaboon J, Siangliw M, Lanceras-Siangliw J, Sirithunya P, et al. Breeding the Thai jasmine rice variety KDML105 for non-age-related broad-spectrum resistance to bacterial blight disease based on combined marker-assisted and phenotypic selection. Field Crops Res. 2012;137:186-94.

Wongsaprom C, Sirithunya P, Vanavichit A, Pantuwan G, Jongdee B, Sidhiwong N, et al. Two introgressed quantitative trait loci confer a broad-spectrum resistance to blast disease in the genetic background of the cultivar RD6 a Thai glutinous jasmine rice. Field Crops Res. 2010;119(2-3):245-51.

Xi ZY, He FH, Zeng RZ, Zhang ZM, Ding XH, Li WT, et al. Development of a wide population of chromosome single-segment substitution lines in the genetic background of an elite cultivar of rice (Oryza sativa L.). Genome. 2006:49:476-84

Yang Z, Sun X, Wang S, Zhang Q. Genetic and physical mapping of a new gene for bacterial blight resistance in rice. Theor Appl Genet. 2003;106:1467-72.

Yi M, Nwe KT, Vanavichit A, Chai-arree W, Toojinda T. Marker assisted backcross breeding to improve cooking quality traits in Myanmar rice cultivar Manawthukha. Field Crops Res. 2009;113:178-86.

Yuan HY, Chen XP, Zhu LL, He GC. Identification of genes responsive to brown planthopper Nilaparvata lugens Stål (Homoptera: Delphacidae) feeding in rice. Planta. 2005:221:105-12

Zong G, Wang AH, Wang L, Liang GH, Gu MH, Sang T, et al. A pyramid breeding of eight grain-yield related quantitative trait loci based on marker-assistant and phenotype selection in rice (Oryza sativa L.). J Genet Genom. 2012;39:335-50

\section{Submit your manuscript to a SpringerOpen ${ }^{\circ}$ journal and benefit from:}

- Convenient online submission

- Rigorous peer review

- Immediate publication on acceptance

- Open access: articles freely available online

- High visibility within the field

- Retaining the copyright to your article

Submit your next manuscript at $\gg$ springeropen.com 